\title{
The Role of International Organizations in Promoting Effective Dispute Resolution in the 21st Century
}

\author{
Locknie Hsu*
}

\begin{abstract}
This chapter posits that international organizations (IOs) can be positive role models in the promotion of effective dispute resolution in a number of ways. The Asian Infrastructure Investment Bank, an IO which is of relatively recent vintage, has the advantage of being able to study and absorb best practices in all international and specialist dispute settlement tribunals. It also stands poised to articulate a set of best aspirations and to transform them through implementation into reality.
\end{abstract}

A New Canvas for the Asian Infrastructure Investment Bank

As one of the newest multilateral banks to be established, the Asian Infrastructure Investment Bank (AIIB) stands at a critical juncture of global economic and institutional reform. Calls for institutional and rule reform have arisen in the contexts of international organizations and systems which have functioned relatively unchallenged for decades. New economic alliances and arrangements are forming and being re-formed as nations adjust to the new environment. Examples of such arrangements include the Comprehensive and Progressive Trans-Pacific Partnership Agreement (СРTPP) and the Belt and Road Initiative (BRI). ${ }^{1}$ The latter has, in particular, thrown the need for

* Locknie Hsu, professor of Law, School of Law, Singapore Management University, lockniehsu@smu.edu.sg.

1 The сртрр has been signed by eleven countries: Australia, Brunei, Canada, Chile, Japan, Malaysia, Mexico, New Zealand, Peru, Singapore, and Vietnam. It came into effect on 30 December for Australia, Canada, Mexico, New Zealand and Singapore and on 14 January 2019 for Vietnam. The СРтPP arose from the earlier Trans-Pacific Partnership (TPP) Agreement, which had also included the US, and which had been signed in 2016. In 2017, the US announced that it would withdraw from the TPP. See Office of the United States Trade Representative, 'TTP'. The Belt and Road Initiative (formerly known as the 'One Belt, One Road')

(C) ASIAN INFRASTRUCTURE INVESTMENT BANK (AIIB), 2019 | DOI:10.1163/9789004407411_008

This is an open access chapter distributed under the terms of the CC-BY-NC 4.o License. 
infrastructure development in the countries within its sphere into sharp relief. Against this backdrop, the AIIB stands poised to be a trend-setter, as a new multilateral organization charged with financing some of these infrastructure needs.

At its disposal is a toolbox, comprising systems, mechanisms and rules to allow it to become such a role model. In addition, the AIIB has the benefit of being able to draw lessons from the experiences of other IOs and dispute settlement mechanisms. To this end, a comparative grid of dispute settlement system features and how other IOs provide for them could be drawn up, for the AIIB to have a comprehensive way to glean the best rules, practices and ideas. This chapter examines the development of such an ethos, the potential for the AIIB to be a role model in the area of dispute settlement, its potential role in promoting non-adversarial dispute settlement methods and dispute avoidance and the possibilities offered by technology which the АІІв may tap to provide strong and efficient dispute settlement mechanisms and facilities.

IOs such as the АІІв can also contribute to international law and the rule of law. At a practical level, the application of legal rules and strictures in an IO may lead to some tensions in dispute settlement. For example, a balance needs to be sought between legalistic processes (which may promote certainty) and flexibility (which may promote greater fairness in result). Another area of potential tension is in the need to balance transparency in proceedings with legitimate concerns over confidentiality. The AIIB can adopt both an ethos as well as methods which can have a positive effect both within and outside itself.

\subsection{Promoting a Distinct Organizational Ethos in Dispute Resolution}

IOs can promote positive values in dispute settlement. While the AIIB would not be the first or alone in doing so, it is in a unique position to both observe the existing good work of other IOs as well as provide its own thought leadership and actions. ${ }^{2}$ The AIIB, for example, is in a position to establish a distinct ethos to guide its dispute settlement mechanisms and procedures. Such an ethos can lead to the articulation of norms for such mechanisms, and norms can in turn be reflected in specific rules within the AIIB mechanisms. Transparency about such an 'ethos-norms-rules' system can inform and influence decisions both in and outside the AIIB.

Initiative, was announced by China's President Xi Jinping in 2013, as an international cooperation initiative knitting together more than 60 countries in Asia, Europe and Africa, featuring facilities connectivity, policy coordination, people-to-people bonds and other collaborative activities. See for example, China's Ministry of Foreign Affairs, 7 September 2013.

2 See, for example, the work of the World Bank and the European Bank for Reconstruction and Development (EBRD). World Bank Group, 1 November 2009; E BRD, 'Our Values'. 
Just as the AIIв has espoused general 'Lean, Clean and Green' core values, ${ }^{3}$ a distinct ethos and related norms could be highly influential in the area of dispute settlement. As examples of its core values, the AIIB has already pledged that it will fight corruption, ${ }^{4}$ support sustainable energy in Asia, ${ }^{5}$ and maintains a framework on environmental and social sustainability. ${ }^{6}$ These form part of its declared ethos. Beyond this, the AIIB will need to ensure that this ethos permeates its projects and is implemented in actual norms. Finally, the specific rules on governance and dispute mechanisms will further reflect these norms. For example, in translating the core value to fight fraud and corruption, clear norms (such as detailed explanation of what might constitute fraud or corruption) and procedures for reporting such activities have been established by the Bank. ${ }^{7}$ The central document reflecting such core values and norms is the Policy on Prohibited Practices, which sets out in detail the prohibited practices, and procedural mechanisms for reporting and dealing with them.

It is suggested that a similar approach can be taken with regard to dispute settlement by the AIIB, namely, to set out the 'core values' (ethos) which it would adopt with regard to settling disputes (whether internal, or with external parties), ${ }^{8}$ fleshed out in a policy document with appropriate procedural systems. This could be another prong of its existing Policies/Strategies. ${ }^{9}$

An example can already be seen in the AIIB's Project-Affected People's Mechanism (PPM), which contains a number of guiding principles:

- Integrity: To operate transparently, with impartiality, independence, fairness, honesty and professionalism.

- Inclusion: To encourage project-affected people to participate in, and benefit from, the development process in a manner consistent with local conditions, including promoting equity of opportunity and non-discrimination and embracing action to remove barriers affecting vulnerable groups.

- Pre-emption: To operate in a collaborative, proactive and preventionoriented manner.

- Proportionality: To ensure that application of the environmental and social framework uses an approach that is appropriate to the nature and scale of

3 See AIıв, Code of Conduct for Bank Personnel 2016.

4 See AIIB, 'Commitment to Fight Corruption', 20 December 2018.

5 See AII B, 'Energy Sector Strategy', June 2017.

6 See AIIв, 'Environmental and Social Framework', February 2016.

7 See AIIв, 'Report Fraud and Corruption'.

8 The АІІв, like other IOs, deals with a variety of dispute contexts, including those relating to employment, procurement and operational financing. The AII B would, like other MDBs, also enjoy a number of privileges and immunities, including the removal of certain disputes from the purview of national courts.

9 For the existing Policies and Strategies, see АІІв, 'Policies and Strategies'. 
the project and reasonably reflects the level of the project's potential environmental and social risks and impacts.

- Continuous learning for effectiveness: To ensure that lessons learned from PPM interventions meaningfully inform and improve AIIB operational activities, directives and policies through continuous, practical and targeted feedback and knowledge sharing to prevent future grievances and harm.

Such guiding principles can be adapted, augmented and developed into a more general set of values for general dispute settlement by the АІгв.

\subsection{IOs as Agents of Positive Influence: The AIIB as a Role Model}

IOs can provide exemplary rules and practices in their own dispute resolution mechanisms, such as establishing systems which uphold the rule of law, provide effective dispute resolution rules and procedures, and promote values such as access to justice, fairness and transparency. As a relatively new institution, the AIIB has the opportunity to 'start with a clean slate', to decide on its stance regarding matters such as those mentioned below, drawing lessons from debates, rules and issues that have been seen elsewhere. The following are some matters which IOs such as the AIIB would need to consider at an early stage, both for the design as well as implementation of a dispute resolution system:

- The provision of clear institutional rules and procedures which, at the same time, provide a suitable degree of flexibility, and which allow for timely changes to improve the system when necessary;

- Designing a system which is accessible and affordable for disputants;

- Ensuring reasonable efficiency in the resolution of disputes through, for example, the setting of clear time-lines, which at the same time allow for a degree of flexibility for more complex cases;

- Addressing issues of due process, fairness and transparency;

- What roles, if any, there could be for third parties (non-disputants) and amicus curiae;

- Handling conflicts of interest issues early, with clarity and transparency;

- Selection of adjudicators-qualifications, expertise and diversity and remuneration method;

- Certainty and predictability in decision-making;

- Whether there should be an appellate process and if so, the method of selection and remuneration for members of an appellate body/tribunal;

- Ease of availability of decisions/outcomes of disputes;

- Whether there should be an early determination process for clearly unmeritorious claims;

- Affordability; and 
- Third-party funding - whether to require disclosure, by whom, of what information, and other related matters in a dispute. ${ }^{10}$

The above illustrate a selection of matters which have, at one time or another, been debated in the international arbitration context, some of which have been more heavily debated in the specific context of investor-State arbitration. ${ }^{11}$ Each aspect needs to be carefully considered and discussed, drawing where possible, lessons from other dispute settlement experiences elsewhere.

As an example, arbitration is envisaged as a method which the AIIB will make use of. This can be seen in the AIIB's General Conditions for Sovereignbacked Loans, where arbitration under the UNCITRAL Arbitration Rules has been stipulated as the method for dispute resolution. It is therefore prudent for the AIIB to consider, and to address well, some of the above issues which have been raised in arbitrations outside the АІІB context.

Secondly, IOs can encourage dispute resolution systems of related stakeholders/clients to adhere to such values. As a key finance provider in large-scale projects, IOs such as the AIIB are in a position to influence various stakeholders in dispute settlement. A good example can be seen in the AIIB's PPM $^{12}$

As an example, the World Trade Organization (WTO) system features a twotier system comprising panels and an appeal level, to ensure a degree of consistency in decision-making. The system also features the use of timelines to promote timely and efficient disposal of complaints. ${ }^{13}$ Several of these features have been emulated in the Association of Southeast Asian Nations (ASEAN) Protocol on Enhanced Dispute Settlement. ${ }^{14}$

Thirdly, IOs have the opportunity to promote goals such as inclusiveness in non-adversarial dispute resolution, as well as dispute avoidance, both with a view to more lasting solutions. As an example, the WTo's dispute settlement rules provide for States' to enter into 'consultations' in the first instance. ${ }^{15}$ Should such consultations fail to yield a mutually acceptable settlement,

10 In the realm of investor-State dispute settlement, the use of third-party funding for disputants has been garnering increasing interest. See, for example, Chan, November 2018.

11 See, for example, Kalicki and Joubin-Bret 2015. A UnCitral Working Group is also currently examining the possibility of investor-State dispute reform: see UNCITRAL, 'Investor-State Dispute Settlement Reform'.

12 See алів, 'Draft Project-Affected People's Mechanism'.

13 See generally, wTo, 'Dispute Settlement'; wто, 'Introduction to the Dispute Settlement System'.

14 See ASEAN, Protocol on Enhanced Dispute Settlement Mechanism 2012.

15 The rules are known as the Understanding on Rules and Procedures Governing the Settlement of Disputes; see wTo, Uruguay Round Agreement: Dispute Settlement Understanding 1994 . 
a State may then proceed to a more adversarial process, by requesting the establishment of a panel to hear the complaint. The rules also provide explicitly for the suspension of such proceedings in favour of negotiations, should the disputing parties wish to further attempt to settle the matter.

Next, drawing from the experience in the context of construction contracts, the use of 'dispute boards' as a means to avoid a contentious dispute from arising or escalating can be seen in some rules. An example is the International Chamber of Commerce's use of dispute boards, which allow contracting parties to, at an early stage, appoint a dispute board which tracks the life of the contract, helping to resolve any conflicts at an early stage. ${ }^{16}$

As another example, in October 2018, the Government of Singapore launched an Infrastructure Asia office to act as a clearing house of information on infrastructure project opportunities in the Asian region. Concomitantly, the Singapore Infrastructure Dispute Management Protocol was also launched, to provide a system of dispute avoidance and settlement for such projects. ${ }^{17}$

The Protocol adopts the dispute board model in that it allows parties to agree to appointment of a dispute board at the start of a project, before any dispute has arisen. This allows such a dispute board to follow the life of the project and to help prevent escalation of any dispute. To give an example of how a dispute board under the Protocol can assist parties, a dispute board may undertake a number of actions (unless the parties agree otherwise), including the encouragement of parties to cooperate to ensure the timely and proper completion of contract works, assisting parties in avoiding or resolving differences through

16 See ICc, Dispute Board Rules 2015:

Article 17: Informal Assistance with Disagreements

1 On its own initiative or upon the request of any Party and in either case with the agreement of all of the Parties, the DB may informally assist the Parties in resolving any Disagreements that have arisen during the performance of the Contract. Such informal assistance may occur during any meeting or site visit. A Party proposing informal assistance from the DB shall endeavour to inform the DB and the other Party thereof well in advance of the meeting or site visit during which such informal assistance would occur.

2 The informal assistance of the DB may take the form of a conversation among the DB and the Parties; one or more separate meetings between the DB and any Party with the prior agreement of all of the Parties; informal views given by the DB to the Parties; a written note from the DB to the Parties; or any other form of assistance that may help the Parties resolve the Disagreement.

3 If called upon to issue a Conclusion in connection with a Disagreement on which it has provided informal assistance, the DB shall not be bound by any views, whether expressed orally or in writing, that it may have given in the course of its informal assistance, nor shall it take into account any information that has not been available to all Parties.

17 See Singapore Ministry of Law, 'Protocol Launched', 23 October 2018. The text of the Protocol see Singapore Dispute Protocol. 
informal discussions with the aim of preventing these from escalating into disputes and facilitating resolution of actual disputes through mediation or the issuing of an opinion or determination. ${ }^{18}$

In addition, a dispute board may also meet senior representatives of the parties informally, assist parties in clarifying, scoping and articulating the ambit of their differences, review with the parties the risks and consequences arising from the differences for the performance of their contract and recommend specific processes and measures to resolve the differences. ${ }^{19}$

The use of mediation can be promoted by IOs such as the AIIB, as mediation is non-adversarial in nature, and can help preserve relationships between disputants. With the expected signing of the UN Convention on International Settlement Agreements Resulting from Mediation (to be known as the 'Singapore Convention' for short) in Singapore in August 2019, ${ }^{20}$ it is expected that mediated settlement agreements will become easier to enforce in Convention signatory countries. As a related measure, to derive the most benefits from use of mediation in the AIIB, suitable capacity-building exercise may be required to ensure that mediators who are appointed are familiar with the areas of law and practice (for example, infrastructure, project finance, investment and international law), since mediators of commercial disputes may lack exposure to these areas. As a related matter, the AIIB could also consider how to ensure diversity in the selection and appointment of mediators in its dispute resolution systems.

2

\section{Harnessing Technology for Efficiency and Transparency in Dispute Resolution}

IOs of the 21st century, like private organizations, have at their disposal an increasing and unprecedented array of technological tools to promote the above values and goals, as well as to speed up dispute resolution processes. The adoption of appropriate technology can be considered in a wide number of areas, such as in case management, online hearings and recording and translating of evidence. Indeed, at the national level, a number of courts are already making use of technology to speed up processes and to increase transparency of and access to their services and facilities. ${ }^{21}$

18 See Singapore Dispute Protocol, para 2.

19 See ibid, para 5.

20 See Singapore Convention; Singapore Ministry of Law, 'Convention Named after Singapore', 21 December 2018.

21 For example, the use of technology in the Supreme Court of Singapore, see Singapore Supreme Court, 'Technology'. 
As an example, ease of web and other access to grievance mechanisms and other processes could be provided, to allow for ease of use and for broader reach. Where possible, the AIIB could explore the facilitation of online access of related materials and by allowing such access in a variety of languages, given that those seeking the use of such mechanisms may not be familiar with the English language. Other aspects of ensuring access relate to the availability of online information explaining the systems, rules and case outcomes and other reports. Access in both technical and non-technical explanations, such as those provided in the WTO website, could also be useful features to include.

IOs themselves can share their own best practices, as well as encourage learning of other organizations' best practices in dispute resolution. As an example, the AIIB could, for instance, create a platform for such sharing, both online, as well as its annual Aпıв Legal Conference, in order to better disseminate these ideas and practices. It is necessary for a system to be open to necessary review and improvement from time to time. This will ensure that an IO's dispute settlement system remains responsive to evolving disputes landscapes and to lessons learnt during implementation in its early years. As a matter of self-review, the AIIB could also, for example, establish an internal scorecard with regard to its dispute settlement list of objectives, values and process targets, so as to maintain an internal review of its systems. Finally, it may also establish an information-sharing forum with other IOs as to best practices gleaned from other dispute settlement systems.

\section{Conclusion: Providing Discussion Fora and Training for Stakeholders}

In order to share its ethos and norms with relevant stakeholders, IOs such as the AIIB can take a number of practical steps to establish an ongoing 'conversation' regarding the handling of disputes and to provide training on specific matters, such as the meaning of due process, transparency and other important values it may espouse. A first step could be to identify the relevant stakeholders and their representatives for such exercises, and these may include compliance officers and grievance-handling officers in partner organizations, co-funders and private-sector partners.

As the AIIB grows in experience and engagement through an increasing number of projects, the role of dispute settlement will be increasingly important. The AIIB stands at an important juncture as a relatively new institution, as it can both establish its own dispute settlement ethos, norms and procedures, as well as draw important lessons and best practices from systems 
elsewhere, whether in the multilateral development bank context, or beyond. Indeed, as this chapter has set out to demonstrate, it would be prudent to draw lessons from a variety of international dispute settlement systems, given the richness of debate and improvements which such other systems have either introduced, or are in the process of considering.

\section{Reference List}

AIIB, AIIB Code of Conduct for Bank Personnel 2016 (AIIB 2016) <www.aiib.org/en/ about-aiib/basic-documents/_download/code-of-conduct/basic_document_code _of_conduct_personnel.pdf> accessed on 12 February 2019.

AIIB, 'Environmental and Social Framework' (AIIB, February 2016) <www.aiib.org/ en/policies-strategies/framework-agreements/environmental-social-framework .html> accessed on 3 January 2019.

AIIB, 'Energy Sector Strategy' (AIIB, June 2017) < www.aiib.org/en/policies-strategies/ strategies/sustainable-energy-asia/index.html $>$ accessed on 3 January 2019.

AIIB, 'Commitment to Fight Corruption' (AIIB, 20 December 2018) <www.aiib.org/en/ news-events/news/2018/20181210_oo1.html> accessed on 3 January 2019.

AIIB, 'Draft Project-Affected People's Mechanism' (AIIB) < www.aiib.org/en/policies -strategies/_download/consultation/draft-AIIB-complaint-handling-mechanism .pdf> accessed on 15 January 2019.

AIIB, 'Policies and Strategies' (AIIB) < www.aiib.org/en/policies-strategies/> accessed on 15 January 2019.

AIIB, 'Report Fraud and Corruption' (AIIB) <www.aiib.org/en/about-aiib/who-we -are/report-fraud-corruption/index.html > accessed on 15 January 2019.

ASEAN, 'Protocol on Enhanced Dispute Settlement Mechanism' (ASEAN, 18 June 2012) <https://asean.org/?static_post=asean-protocol-on-enhanced-dispute-settle ment-mechanism $>$ accessed on 12 February 2019.

Chan D, 'Three "Pitfalls" for the Unwary: Third-Party Funding in Asia' (Law Gazette, November 2018) <https://lawgazette.com.sg/feature/three-pitfalls-for-the-unwary -third-party-funding-in-asia/> accessed on 15 January 2019.

China's Ministry of Foreign Affairs, 'President Xi Jinping Delivers Important Speech and Proposes to Build a Silk Road Economic Belt with Central Asian' (China's Ministry of Foreign Affairs, 7 September 2013) <www.fmprc.gov.cn/mfa_eng/topics_665678/ xjpfwzysiesgjtfhshzzfh_665686/t1076334.shtml> accessed on 12 February 2019.

EBRD, 'Our Values' (EBRD) < www.ebrd.com/our-values.html> accessed on 12 February 2019 .

ICC, ICC Dispute Board Rules 2015 (ICC, 1 October 2015) <https://iccwbo.org/dispute -resolution-services/dispute-boards/rules/\#article_16> accessed 24 February 2019. 
Kalicki J E and Joubin-Bret A, 'Introduction TDM Special issue on "Reform of InvestorState Dispute Settlement: In search of a Roadmap"' (Transnational Dispute Management) <www.transnational-dispute-management.com/article.asp?key=2023> accessed on 12 February 2019.

Office of the United States Trade Representative, 'Trans-Pacific Partnership (TPP)' (USTR) <https://ustr.gov/trade-agreements/free-trade-agreements/trans-pacific -partnership $>$ accessed on 12 February 2019.

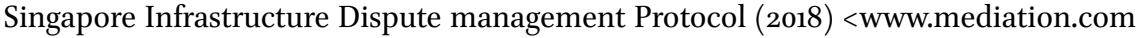
.sg/assets/downloads/neutral-evaluation-2/SIDP-Protocol-Bklet-A4-221018-C.pdf> accessed on 3 January 2019.

Singapore Ministry of Law, 'New Singapore Dispute Protocol Launched to Minimise Time and Cost Overruns in Infrastructure Projects' (Singapore Ministry of Law), 23 October $2018<$ www.mlaw.gov.sg/content/minlaw/en/news/press-releases/launch -of-SIDP-reduces-time-and-cost-overruns-in-infrastructure-projects.html > accessed on 3 January 2019.

Singapore Ministry of Law, 'Singapore clinches bid for UN Convention on Mediation to be named after Singapore' (Singapore Ministry of Law 21 December 2018) <www .mlaw.gov.sg/content/minlaw/en/ news/press-releases/UN-convention-on-media tion-to-be-named-after-Singapore.html > accessed on 18 January 2019.

Singapore Supreme Court, 'Technology' (Singapore Supreme Court) <www.supreme court.gov.sg/services/visitor-services/court-facilities/technology> accessed on 12 February 2019.

UNCITRAL Working Group III, '2017 to present: Investor-State Dispute Settlement Reform' (UNCITRAL) <www.uncitral.org/uncitral/en/commission/working_groups/ 3Investor_State. html > accessed on 12 February 2019.

UN Convention on International Settlement Agreements Resulting from Mediation in UNGA 'Report of the United Nations Commission on International Trade Law' (25 June-13 July 2018) 51st Session UN DOC Supp No A/73/17.

World Bank, Living our values: code of conduct (Report No. 62411, World Bank, 1 November 2009) <http://documents.worldbank.org/curated/en/147281468337279671/ Living-our-values-code-of-conduct $>$ accessed on 12 February 2019.

WTO, 'Dispute Settlement'(WTO) < www.wto.org/english/tratop_e/dispu_e/dispu_e .htm $>$ accessed on 12 February 2019.

WTO, 'Introduction to the Dispute Settlement System' (WTO) < www.wto.org/english/ tratop_e/dispu_e/disp_settlement_cbt_e/cisıpı_e.htm $>$ accessed on 12 February 2019 .

WTO, 'Uruguay Round Agreement: Understanding on Rules and Procedures Governing the Settlement of Disputes' (WTO) <www.wto.org/english/docs_e/legal_e/28 -dsu_e.htm $>$ accessed on 12 February 2019. 